\title{
Disentangling the HIV-1 human protein interaction networks and their implications in the dynamics of viral replication and pathogenesis
}

\author{
Devi Priyanka Maripuri, Daniel Alex Anand \\ From 2nd International Science Symposium on HIV and Infectious Diseases (HIV SCIENCE 2014) \\ Chennai, India. 30 January - 1 February 2014
}

\section{Background}

Network biology has broadened our view and changed our perspective in understanding disease. A systems perspective is imperative to the understanding of the dynamics of viral pathogenesis and host interactions. Probing the complex web of HIV-1 - host protein interactions divulged biologically meaningful results.

\section{Methods}

Global and protein specific networks were constructed using the HIV-1, Human Protein Interaction Database. The networks were visualized and analyzed using cytoscape and its plug ins. Functional annotation and enrichment analysis were performed using DAVID. Protein Sub cellular locations were determined using the LOCATE database.

\section{Results}

Sixteen HIV-1 proteins interacted with 2545 human proteins, of which 3668 (34.53\%) were direct and 6340 (65.46\%), regulatory interactions. Seventy seven different types of interactions with $\mathrm{T}$ cell surface glycoprotein CD4 isoform 1 precursor (276/10008) and DNA dC->dU editing enzyme APOBEC-3G(109) being the top two interacting proteins. The top interacting HIV-1 proteins were tat, p14 (28\%) followed by gp120 and nef p27. Functional annotation returned 312 clusters with highest enrichment scores of 30.71 for positive regulation of apoptosis ( $p$ value 7.9E-32). Toll like receptor and the Jak sTAT signaling pathways were most crucial to host response. LOCATE identified 491(10.7\%) nuclear

\footnotetext{
* Correspondence: danielalexanand@gmail.com

Department of Bioinformatics, Sathyabama University, Chennai-600119, India
}

proteins, 419(9.15\%) cytoplasmic, 295 (6.44\%) membrane and 190(4.15\%) extracellular proteins.

\section{Conclusion}

Network theory and application is critical in understanding host - viral dynamics. Integration of the interaction networks, expression data, cell type, disease stage and other factors are bound to enable phenomenal insights that would accelerate the development of highly effective therapeutic interventions.

Published: 27 May 2014

doi:10.1186/1471-2334-14-S3-P61

Cite this article as: Maripuri and Anand: Disentangling the HIV-1 human protein interaction networks and their implications in the dynamics of viral replication and pathogenesis. BMC Infectious Diseases 2014

14(Suppl 3):P61.

Submit your next manuscript to BioMed Central and take full advantage of:

- Convenient online submission

- Thorough peer review

- No space constraints or color figure charges

- Immediate publication on acceptance

- Inclusion in PubMed, CAS, Scopus and Google Scholar

- Research which is freely available for redistribution 